\title{
The Magic of Social Life: Online Topics and Resources
}

\author{
Brian Rappert \\ University of Exeter
}

\begin{abstract}
The global COVID-19 pandemic has compelled magicians to reconsider how they engage audiences. The pivot to online delivery platforms has served as another occasion in the history of this art form to consider long running questions about its aims and means. This article elaborates the reasoning behind one effort to produce an online, Zoom-based resource prompted by the COVID-19 pandemic; namely a series of interactive recorded performances titled The Magic of Social Life. It does so in two parts: (i) outlining the rationale for a form of academic magic that seeks to turn commonplace social conventions into topics for discussion, and (ii) elaborating how this form of magic was further developed to promote reflection on technologically mediated performances. Through examining the choices and commitments associated with both parts, this article furthers efforts to theorise magic as a form of social interaction.
\end{abstract}

\section{KEYWORDS}

deception, reflexivity, social interaction, concealment, magic 


\section{INTRODUCTION}

As an activity that typically aims to stage what is regarded as improbable or impossible, entertainment magic has long been recognised as interwoven with the cultural beliefs of its day (Bell 2012; Lamont 2013; Smith 2015). 'Modern conjurors' marshal what is widely held to be the case (and what is not) in order to astound. As part of this overall dynamic, developments in technology have both expanded the ways in which magic is performed and enabled new forms of simulation and dissimulation (During 2002; Steinmeyer 2003; Mangan 2007; Jones 2011).

At the time of writing this article, the restrictions associated with public gatherings due to the global COVID-19 pandemic have required magicians to reconsider how they meet their audiences. In particular, many have pivoted to offering online performances through Zoom and related communication platforms. As with the advent of radio, TV and social media magic, this intensification of online performances provides another occasion in the history of this art form to consider long running questions such as: How does the adoption of new means of delivery challenge and preserve performance traditions? In what ways can artistry be aided with and replaced by technology? How are standards for what counts as skilful being transformed as well as reproduced? Who contributes their labour to the production of magic and who gets rewarded? ${ }^{1}$

Against this historical backdrop, this article elaborates the reasoning behind one effort by the author to produce an online educational website prompted by the COVID-19 pandemic; namely a series of recorded interactive performances titled The Magic of Social Life. Reflecting my background, this website aims to employ magic as a way of illustrating theories and concepts in the social sciences as well as using those theories and concepts to appreciate how magic is accomplished.

In recounting the rationale and experiences with The Magic of Social Life as part of this Special Issue, this article has three aims for those theorising magic:

- to elaborate additional rationales for the sub-genre of 'academic magic' (Landman 2018) and thereby propose additional purposes modern conjuring can serve;

- to further the conceptual understanding of magic as a form of social interaction;

\footnotetext{
${ }^{1}$ These are not questions unique to magic, see, for instance, Pye (2010) and Cashman (2011).
} 
- to set out how notions of the contrived and the natural as well as topic and resource can blend together in online delivery platforms.

\section{ORIGINS}

This section begins by setting out some of the background for my engagement with magic, so as to understand the motivations for and assumptions underpinning The Magic of Social Life. This website was the result of the first three years of my efforts to learn magic. In late 2017, as someone with no prior familiarity with conjuring methods, I began practising (largely) card magic. In line with other 'self-' or autoethnographic studies (e.g., Sparkes 2000), I sought to use my embodied efforts as a way into examining the forms practical reasoning associated with acquiring skills (Livingston 2008).

In doing so, I adopted a particular orientation to expertise. Rather than spending years developing my skills so as to offer an authoritative account of modern conjuring - the commonplace justificatory premise for instructional books, autobiographies and theorisations - I sought to ground my analysis on ignorance and a distinct lack of proficiency. Assuming the status of a novice is a commonplace basis for study of skill acquisition in qualitative social science traditions (e.g., O'Conner 2005; Atkinson 2013). In-line with such traditions, through reflecting on my ongoing struggles to move from novice to some level of competency, an initial hope was that I would be sensitive to subtleties that might have become forgotten or unappreciated by seasoned hands. ${ }^{2}$ In this way, my inexperience was positioned as a strength.

However, what I did not appreciate at the start was the nuanced positioning of expertise within magicians' reflections on their art. In particular, I did not appreciate how performers contest $w$ ho is able assess performances through the eyes of (lay) audiences. As magicians typically seek to generate awe and wonder in others, they need to be able to adopt the perspectives of their audiences in order to assess what works. Yet, being able to do so is not straightforward given the use of secreted methods only meant to be known to the performer. The centrality of hidden methods to magic means that performers and audiences typically have highly divergent understandings of what is taking place during a performance. While proficiency in being able to interpret magic from the perspectives of (lay) audiences is often portrayed as deriving from performance experience, such experience is also often said to result in a kind of learnt inability to gauge magic. As Ortiz argued the 'moral

\footnotetext{
${ }^{2}$ Conversely, too, by bringing to bear theoretical concerns in the social sciences concerning how knowledge is acquired and organised, I sought to be sensitive to certain subtleties that might go unappreciated by unseasoned hands too.
} 
here as elsewhere is that magicians generally are less perceptive audiences than laypeople and an unreliable guide as to what constitutes strong magic' (Ortiz 1994: 244). ${ }^{3}$ Performers are not reliable judges of magic for lay audiences because of their familiarity and fascination with method (e.g., Shezam 2019). Underlying such arguments about acumen are long standing doubts about the possibilities for reliably reading audiences' surface reactions (Vernon 1940; Brown 2003; Armstrong 2019). Rather than signalling gratitude, applause can express a willingness to please performers. Rather than signalling indifference, silence can mark deep engagement (Olewitz 2020).

If the extent of a performer's experience is not a straightforward measure of their perceptiveness, then neither is the lack of familiarity with method taken as straightforward measure of the obtuseness of audiences. While lay audiences might not be able to discern the exact methods for tricks, it is argued by professionals that they possess an acute ability to discern give-away actions and minute hesitations (Ortiz 1994).

Within my development as a performer, the matter of who can rightfully speak for audiences and who can claim expertise have come to the fore in another respect. Based on what I have read of analyses of conjuring - in both practitioner and academic publications - it is my conclusion that it is those performing magic that ty pically speak for what audiences experience (see Rolfe 2014). Outside the parameters of experimental psychology (Kuhn 2019), primary scholastic research directly with audiences is comparatively limited. Historical studies of magic offer accounts of audiences' experiences, but are necessarily reliant on the contingencies of what survives as records (Lamont 2013). Performers, of course, have considerable information on which to base their claims about audiences, but the aforementioned concerns about the ability of professionals to read audiences place a question mark over what can be concluded on the back of performers' reading of audiences alone.

As a result of the considerations in this section and others, since starting magic in 2017 I have sought ways to make audiences' experiences central to my studies. The next section elaborates a prime means by which this was done that directly informed the composition of The Magic of Social Life.

\section{MAGIC AS INQUIRY}

In early 2018 I began recording small group shows for (largely fellow academic) acquaintances in a parallel manner to how amateurs often begin by

\footnotetext{
${ }^{3}$ Emphasis in original.
} 
performing for their acquaintances. ${ }^{4}$ I analysed these sessions as forms of 'social interaction'. This term signals the manner in which I approached the sessions as encounters of reciprocal influence wherein the unfolding actions of participants and I were not understood as independent from one another. In doing so, my approach furthered previous efforts (Nardi 1988; Jones 2011) to conceptualise magic as a social interaction. Unlike Nardi (1988), however, I did not conceive of the interactions of conjuring performances as a zero sum aggressive contest of power in which magicians engage in unidirectional forms of control. Instead I sought to approach magic as involving a mix of efforts involving control and mutual cooperation (Rappert 2021a).

To make audiences' experience a core concern, my sessions took the format of focus groups in which I served as both performer and conversation moderator (Rappert 2021a). Individual tricks were interspersed with the questioning of participants' experiences. In adopting this format, the intention was to promote learning within and between sessions. As for learning within, the focus group format provided opportunities for individual participants to voice their reflections in emerging dialogue with others. Through my prodding questions about their experiences, participants responded in ways that went beyond the typical (dis-) affiliation displays that often follow tricks (for instance, applause, laughter). Instead of just being with the activity at hand, participants were asked explicitly to account for what it meant to be involved in it. As someone seeking to learn about how audiences experience magic, an advantage of this unconventional format was that feedback was integral to the overall performance rather than feedback needing to be somehow captured subsequently.

It would be naïve though to assume such responses were simply unmediated representations of participants' inner feelings and thoughts, unaffected by the conditions under which they were generated (Rappert 2021a). In part, this concern was addressed through learning between sessions. In the end, 30 sessions with some 70 different participants were recorded. Across these sessions, I modified the questions and overall composition of tricks, patter and dialogue on an ongoing basis in order to make my evolving conclusions into topics of conversation. For instance, in experiencing a limited challenge from participants in the initial sessions, I then started directly asking participants to account for how they acted vis-à-vis seeking to disrupt or sabotage tricks. I

\footnotetext{
${ }^{4}$ A noticeable feature of my audience was the manner in which participants brought their own theoretical and conceptual frameworks to bear on the interpretation of our actions, frameworks that sometimes served as the basis for participants misdirecting themselves about the mechanisms for the magic effects (See Rappert 2021b).
} 
incorporated a gloss of these responses into still subsequent sessions as a way of promoting participants to reflection on their behaviour by providing a comparison with previous participants.

Within and between sessions then, the overall strategy was to 'topicalise' (Zimmerman and Pollner 1971). By this term, I mean that I sought to shift away from drawing on cultural knowledge, habitualised practices and ordinary conventions as unexamined resources. Instead, at least at times, I orientated to them as topics for joint consideration. For instance, rather than simply performing with the expectation that participants would likely only offer limited form of challenge and disruption, I explicitly asked participants to reflect on and account for their behaviour. Through doing so, otherwise taken for granted ways of acting in the world were made into matters for mutual inquiry. My questioning explicitly drew on themes in sociology, psychology, criminology and other fields in order to foster discussion about our unfolding interactions together. This included, for instance, reference to the social constitution of notions of self and other, the performative dimensions of everyday interactions, the social history of public demonstration and truth, the production of naturalness, the sociology of 'bullshit' and ignorance (Frankfurt 2005), as well as the constitution of authenticity within technologically mediated communication (see below for elaborations).

In spending the majority of our time together discussing participants' reflections (rather than undertaking the tricks themselves), the composition of these sessions differed considerably from most commercial performances. They also differed with regard to my starting intent as a performer. While many performers might take magic as an activity that entails using seemingly ordinary objects to imagine extraordinary possibilities (Neale 2008), I sought something of the reverse. My aim was to foster an appreciation of the ordinary - ordinary here refers to the commonplace, often tacit, ways by which we as human beings act together. For a sociologist such as myself, the ongoing accomplishment of mundane interactions is 'magical' in its own way. In seeking to turn attention to what was taking place there and then in the performance of magic, I sought a form of engagement that would encourage participants to reflect on their mundane and generally taken-for-granted experiences anew. Writing about magic in the modern day, Augusto Corrieri (2018: 16) described it as 'a form of meta-theatre: intensely and inherently selfreflexive, its raison d'être consists in spectators questioning the act itself, questioning the framework they are caught in, and questioning the scope and limits of their own questioning.' Some magicians, such as Penn \& Teller, have placed the self-reflexive quality of magic at the front and centre of their work 
by selectively revealing the methods behind tricks. In contrast, my sessions sought to further the self-reflexivity in magic through fostering group dialogue that attended to (and thereby helped constitute) our interactions as a group making magic together.

Within this iterative process an experiential and provisional understanding was sought in which I claimed what John Dewey (1929) labelled as 'warranted assertability' for my unfolding conclusions about participants' experiences (see Rappert 2020).

With this basic format and rationale developed in 2018-19, in late 2019 I began to offer paid-for, face-to-face group shows through the Ashburton Arts Centre in Devon, England. Explicitly billed as encounters that sought to use magic as a springboard for encouraging audiences to reflect on everyday life, eight events with an average of 12 participants were held up until mid-March 2020. Judging by the (albeit questionable) indicators of audience behaviour and postevent questionnaire responses, the mixed entertainment-education format proved engaging for those that attended.

\section{TOPICS AND ONLINE INTERACTIONS}

With the COVID-19 lockdown starting in March 2020 in the UK, my sessions moved from face-to-face interactions to technologically-mediated ones by making use of Zoom as a delivery platform. Fifteen sessions were held through the Ashburton Arts Centre and the Exeter Phoenix arthouse by February 2021.

In shifting to online performances, my experiences mirrored that of many amateur and professional conjurors. With this pivot, many in the art have sought to offer guidance and material appropriate for Zoom, Teams and other interactive platforms. As one notable initiative, Video Chat Magic was launched in 2020 by Will Houstoun and Steve Thompson. ${ }^{5}$ Its topics span a range of issues. These include practical and technical matters such as how to arrange lighting, how to design performance backgrounds, which recording equipment to purchase, what operating instructions to give audiences, how to set-up the preferences for platforms, how to ensure that the video quality is appropriate, and so on. What video chat platforms afford and the hazard for performances was another frequent topic for consideration. For instance, the inability of audiences to inspect equipment offers the possibility of easily using specially designed products, but the lack of ability by the audience to inspect

\footnotetext{
${ }^{5}$ See https://videochatmagic.com/
} 
equipment also reduces the potential for amazement. Likewise, the Gallery View setting in Zoom and other platforms allows performers to see audience members together in a way that is not possible in live settings, but also confounds assessing the group's reactions (e.g., McCabe 2020).

As is evident in many of the items in Video Chat Magic, online platforms are posing fundamental questions about what it means to be with others in performance settings. For instance, the manner in which audiences are often muted to avoid disruptive noise changes performances for everyone. The absence of applause, for instance, undercuts the commonplace tension-release dynamics constitutive of many performances. As a result, magicians need to find alternative ways of prompting and displaying audience appreciation (Tieber 2020). With this comes artistic differences about what makes for a good interaction, appropriate forms of deception, on so on. ${ }^{6}$

In my case, the entries in Video Chat Magic served as starting material for extending my efforts to make our interactions together into a topic for joint inquiry. For instance, Houstoun and Thompson (2020) examine the conditions for eye contact in video chat platforms. As they note, establishing eye contact is vital for building trust and rapport in many kinds of performances settings. Video chat platforms both enable performers to appear to look into the eyes of audience members (since each participant can see the magician directly in from of them no matter the audience size) and frustrates doing so (since magicians are drawn to look down at the people on computer screen rather than up into the camera lens). In response, Houstoun and Thompson proposed various solutions to establish the pretence of eye contact through getting magicians to look into the camera lens. These include shielding the computer screen with the images of participants, positioning the participant image window as near to the camera as possible in order to minimise angular disparities and (for those that crave audience adulation) reconsideration whether this delivery platform is appropriate.

Stemming from general orientation outlined in the previous section, I have taken a different orientation to the problematics associated with eye contact online. Rather than seeking a technical solution, I have sought to make the problems of contact into a topic for discussion. Consider an example. In my first Zoom-based practice session, I used a camera that focused down onto my table in order for participants to be able to closely watch my card handling. In

\footnotetext{
${ }^{6}$ For instance, as in the unacknowledged use of authentic sounding prerecorded applause, see Thompson (2020).
} 
a post-trick discussion, a participant suggested that the camera view needed to change. One reason she cited was that seeing my eyes enabled her to imagine I was addressing her directly. What proved particularly thought-provoking for me was what she then went on to say: that by seeing my eyes looking at her she could experience a one-to-one connection with me even as she knew full well that I was rarely attending to her. In other words, she felt an affective bond despite the conscious recognition that 'eye-to-eye' contact was not being established. I found this interesting because it indicated the ways in which audiences participate - in this case consciously - in a contrived make-believe about the scene at hand.

Based on this feedback, what I have done is make the co-construction of interpersonal connection into a topic of group conversation within my online sessions. I typically do so in this way: at the end of a trick, I ask participants whether they are confident that they are seeing all that they need to see in the online delivery format. Since virtual shows do not allow for the same kind of visual scrutiny as face-to-face interaction, I am interested in hearing whether participants think online delivery offers any additional possibilities for magicians to deceive. Then, however, I ask participants whether they are seeing more than what is taking place. I do this by relaying the participant's comments in the previous paragraph and then illustrating how the scene appears to them as I vary my gaze between the recording camera and my computer screen. In making the felt experience of eye contact into a topic of conversation, I seek to promote a space for discussing participants' ongoing experiences, expectations, understanding, etc. regarding how we as a group make the activity of magic happen together online through our choice of actions and our interpretations of the actions of others.

\section{BEHIND THE SCENES}

With the previous elaborations of formats and rationales, the remainder of this article discusses one website developed on the back of my face-to-face and online performances called The Magic of Social Life. ${ }^{7}$ In the summer of 2020, the Economic and Social Research Council (ESRC) offered small grants for public engagement events as part of its annual Festival of Social Science week. My proposal to the scheme was to put on interactive Zoom-based sessions along the lines of my public shows. As part of these sessions, I would offer effects ${ }^{8}$ and verbal patter to promote reflection on how magic is an accomplished form of social interaction between the audience and the magician. In doing so, the

\footnotetext{
${ }^{7}$ See https://brianrappert.net/the-magic-of-social-life

${ }^{8}$ In line with commonplace definitions of effects in among practitioners, the term here is refers to what the audience perceives through the overall presentation.
} 
intention was to display directly the relevance of social science concepts associated with inter-subjectivity, symbolic interaction, secrecy and other topics through facilitating reflection -- there-and-then -- on how our interactions together constituted magic. Through packaging recordings of the sessions into small segments, writing accompanying elaborating text, and linking to online social science publications, my plan was to produce a novel resource for communicating social science concepts and theories.

In the end, three sessions were recorded on the same day: one with undergraduate social science students at the University of Exeter (designated 'UG'), another with Exeter members of the group "University for the $3^{\text {rd }}$ Age" (U3A), and one with two university academics and a publishing house editor (AC). For each, I was located at the Ashburton Arts Centre, positioned in front of its main stage. ${ }^{9}$

Before providing an elaborating gloss for what appears on The Magic of Social Life website, the sub-sections in the reminder of this section recount some lessons drawn from the recording and editing process.

\section{The Technical is not Merely Technical}

As commonly noted today, performing and recording Zoom-based magic requires attending to a host of technical considerations associated with the positioning and configuration of lighting, recording equipment, props and other objects. As a first attempt to record outside of my home and as my first collaboration with a technical assistant, practical considerations about the staging of the performances figured heavily in my mind during the recordings.

For the purposes of this article, I want to note how such considerations should not be reduced to being merely 'technical' in nature. Instead, again and again, mundane practical matters with equipment had significant implications in relation to issues of truth, trust and identity.

For instance, take camera views. The original plan was to film the larger session ( $n=8$ participants) with U3A in Speaker View pinned to me during the effects and then to switch to Gallery View during the post-effect conversations. The other two sessions were to be filmed in a 2x2 matrix in Gallery View. In addition, two cameras were fixed on me for the sessions - one face on and the

\footnotetext{
${ }^{9}$ My intent in being in front of the stage rather than on stage was to signal the crafted, theatrical and contrived nature of these sessions.
} 
other to the side. ${ }^{10}$ Speaker and Gallery Views in Zoom provide alternative forms of witnessing. In showing both the performer and members of the audience together, Gallery View allows those looking on to witness the effects, but also to situate their reactions against other audience members. In being able to concentrate more closely on the image of the magician, Speaker View enables fine-grained inspections. By shooting through both views during effects, my hope was to make use of their relative advantages.

This plan did not come to fruition, or at least not in the way I intended. A last minute hiccough with the equipment meant the recording computer needed to be swapped. As a result, the Zoom settings were inappropriate. These last minute alterations also meant I needed to be the one that moved between the cameras, the Zoom views, and whether or not I was pinned; a requirement that proved taxing to undertake during the demands of performing. The result was a diverse array of planned and unplanned recording view configurations. Taken together, these configurations provided ample illustration of the commitments associated with any individual viewing arrangement. For instance, during the video editing I became aware that the session with undergraduate students was filmed through the primary camera on Speaker View but not pinned to me. The result was that when students spoke during effects, the visual recording cut to them. An implication of that was that subsequent viewers of this camera recording would be reliant on the students as guarantors I was undertaking the action I specified (e.g., placing the cards in the appropriate pile). Such a dependency may not (or may) be desirable from the perspective a magician utilizing a modern, naturalistic style seeking to entertain audiences. For me though, as someone seeking to make educational points about social interactions, this dependency offered the opportunity to consider how notions of trust are at stake in technologically mediated forms of witnessing.

\section{Staging is Ever Pervasive}

Despite the overall aim in my face-to-face and online shows of making the interactional aspects of magic into topics for reflection and discussion, this process was not and never could be total. What is brought to the fore in any situation simultaneously displaces other considerations (Rappert 2020b). And so it was the case in The Magic of Social Life. While I sought to turn attention to aspects of how magic was practically accomplished, what counted as legitimate, appropriate, on so to make into a topic for conversation still needed

\footnotetext{
${ }^{10}$ Another (third) camera picked up some segments of the performances in two of the sessions.
} 
to be addressed as part of editing the recordings. While occurrences such as background noise interruptions, the sight of a participant getting up to answer his doorbell, and the reset moments between effects might have been part of the lived experiences of recording The Magic of Social Life sessions, they were not movements I deemed appropriate to feature in the final video clips.

In addition, the appropriateness of presenting mistakes was another matter that needed to be addressed. For instance, in the UG session, Héctor Mancha's (2016) 'Daisy Ending' was performed - an effect that entails restoring the petals on a daisy through undertaking an obscured move during a 'petal storm' created from the previously removed petals. While the audience in the session responded in ways that indicated they did not perceive the move, it was visible in the recording. The resulting disjunction offered varied options. On the one hand, it was an opportunity to ponder a host of important points: the limits of perception, the potential for audiences to act in ways that please magicians, and so on. On the other hand, the flashing of the move also gave away the method which was not mine to give away. In the end, I decided not to include this clip.

\section{Team Construction is Multi-layered}

As Erving Goffman elaborated in his classic book The Presentation of Self in Everyday Life, everyday performances are often enabled by (and help to form) cooperative 'teams'. Who makes up a team can shift over time and also be defined in multiple ways within a single encounter.

This certainly seemed to be the case in the recording of The Magic of Social Life. One team consisted of the technical assistant and I, with the former confined to an out of screen back region. Another team that arguably came into formation consisted of the Zoom audience participants and I. Without intending to do so, during the recording a recurring sense was evoked in me that all of us together were jointly operating within a back region - a back region to those that would eventually watch the recordings online. This notion of a back region shared between us (but not with the audience of the recording) was constructed in various actions I undertook: re-starting tricks due to technical or other hiccoughs, setting up for the next trick through re-arranging materials and consulting notes, offering elaborations of the editing process for the recordings, as well as moderating the pre- and post-recording discussions. It was also created by audience actions such as requesting a short break or excusing themselves for the next part of the show. While impressionistic, my distinct sense was that such actions helped foster a notion of us (magician and 
participants) working together to make a performance for a 'them' (subsequent viewers of the recordings).

In terms of the relevance of team formations, too, in each session at least one participant openly queried whether the other Zoom audience members were in cahoots with me (as in the Challenge effect video clip elaborated in the next session). The expression of concerns about who was 'in-team' were intensely voiced when one effect had to be re-done because it was not recorded the first time around.

\section{THE FINAL PRODUCT}

On the back of the previous sections, this one turns to overviewing the website generated for The Magic of Social Life. In the end, it included eight recorded segments (consisting of tricks plus discussions) along with accompanying text. In this section, I outline the rationale for the thematic framing for each featured tricks in turn as well as identify which features of our interactions became topics of joint consideration. Before reading these commentary glosses, readers are encouraged to visit the website to consider the material presented for themselves.

Clip 1: Witnessing. Based on my experiences of performing magic, in this clip I sought to encourage viewers to treat witnessing as a negotiated social accomplishment. A classic version of 'Triumph' served as the trick. ${ }^{11}$ Through initially recounting some of the aforementioned debates in magic regarding the ability of experienced magicians and lay audiences to assess what is before them (see section two), I asked participants how convincing they found Zoombased magic. In particular, I queried the AC group whether this means of delivery raised any doubts for them about their ability to see what they needed to see in comparison to face-to-face performances. The resultant comments drew on a number of theoretical concepts regarding theories of the mind, front/backstage and infrastructure to make sense of how witnessing was taking place in this and other remote magic sessions. I then asked the participants whether they were seeing more than what was taking place. I did so through offering an account of my first experience of performing over Zoom in relation to eye contact (see section 3). This generated a discussion about how the appearance of connection functioned within our interactions.

\footnotetext{
${ }^{11}$ While there are many cards trick labelled as versions of Triumph, the common effect sought is for deck that appears to consist of cards face up and down to transform such that all the cards are either face up or face down - all cards, that is, expect one which facing in the contrary direction to the others. That opposing card is typically a card previously selected by an audience member.
} 
Clip 2: Concealment Do audiences want to know the methods employed in magic? Why or why not? In my experience of directly asking participants about these questions, I have heard a variety of views. Although most (but certainly not all) people report wanting to know, the grounds for and qualifications associated with knowing vary widely. In this clip, the U3A participants elaborated the reasoning for and tensions associated with learning the secrets of magic. That discussion was prompted by performing Héctor Mancha's 'Personal Triumph' [2016] ${ }^{12}$ and the accompanying patter on my part. In this case the patter took concealment within magic as its subject. Smith's (2015) depiction of modern magic as entailing a 'concealment of concealment ${ }^{\prime 13}$ was offered both as a way of getting U3A participants to reflect on our activity together, but also as a way of justifying repeated displays of the cards as required for the obscured method.

Clip 3: Duality This video with the UG group sought to illustrate how opposites can come together in magic and other activities. Tamariz' 'Happiness' in Verbal Magic (Tamariz and Navarro 2008) served as the effect. The students and I undertook an elaborate set of semi-structured manipulations of a pile of cards that seemed to result in their chaotic disordering. In the end the cards in each of our decks were revealed as sequenced in their original starting order. Within the final composition of The Magic of Social Life, this video itself served another purpose: it helped set up for the next clip entry.

Clip 4: Vulnerability This video contains the end of the performance of Tamariz' 'Happiness' ${ }^{14}$ conducted with the U3A group. Unlike the Duality clip, the effect does not come out as planned - neither the participants nor I managed to get their cards in order. Although not intended, this outcome provided an opportunity to make 'failure' into a topic of conversation. When effects do not turn out as planned, the question of how to respond can be felt as a demanding one for performers. One response is to minimise the mess-up. As Darwin Ortiz (1994: 432) advocated:

When something goes wrong in a performance, your job is to make the audience forget it as quickly as possible. Whining and self indulgently

\footnotetext{
${ }_{12}$ My thanks to Héctor Mancha and Juan Tamariz for permission to use their effects.

${ }^{13}$ In short, Smith elaborates how modern magic relies on the concealment of the methods for effects as well as the concealment that there are any methods in play at all.

${ }^{14}$ In this trick, a packet of ten cards is placed in a pile in order from ace to ten. That package is then subject to a complex mixing in which participants are offered semi-structured choices about exactly how to manipulate the cards. In the end, the packets of everyone doing the trick are revealed to be in their original order from ace to ten.
} 
dwelling on the matter will only impress the screw-up more strongly on their memory. If, instead, you treat the matter as of little importance, they will too. Owing to my interest in using group dialogue to reflect on and constitute social interactions, I opted for an opposing course of action. In this video the trick 'going wrong' became a topic for group conversation. This was done through the notion of vulnerability. I used this occasion to discuss how my sense of vulnerability as a performer. That discussion then set the basis for asking participants about how they experienced vulnerability in playing the role of audience member to a magic show.

Clip 5: Skill This video features me performing a few basic card flourishes for the UG group. The final one involves the cards falling down from one hand to another in a controlled, overlapping manner producing a visual effect sometimes referred to as 'waterfall'. After this effect is produced a few times, I then reveal the deck consists of cards strung together. This pairing of performance-disclosure is used to discuss the role of the visible display of skill in establishing claims to proficiency.

The origins for taking skill as a topic for discussion stem from my initial period in performing magic in 2018. At that time, I only knew so called self-working effects that did not rely on sleight of hand techniques. Despite my lack of any physical technical skill associated with sleights, on various occasions audience members attributed me with physical skill. One prominent justification for this attribution was their inability to detect any sleights (Rappert 2021b). In other words, working with a general expectation for how card magic is done (i.e., through the dexterous card handling), the absence of any sign of it (because the effects were self-working) provided a grounding for my proficiency. My recounting of this experience in the UG session served as a prompt for discussing the relation between proficiency and the appearance of skill.

Clip 6: Challenge In this video, the AC group and I discuss the place of challenge and behavioural norms in conjuring performances. This was done through the use of what Pit Hartling (2003) has called an 'induced challenge'. I undertook a Zener card ${ }^{15}$ prediction effect that had an apparently guessable method in order to encourage audience members to voice their suspicions about the method. When they insisted on visually inspecting the non-predicted cards,

\footnotetext{
${ }^{15}$ Zener cards were originally developed by psychologist Karl Zener in the early 1930s as a way of testing extrasensory perception. The cards have one of a five symbols on their face up side: a circle, and plus sign, three wavy lines, a square and a five-pointed star. In extrasensory perception tests, research subjects were asked to predict the face up symbol while focusing on face down Zener cards.
} 
their suspicions about the method were refuted and the prediction effect was strengthened. In my case, though, the inducement of challenge was not primarily intended as a means of exercising control over the audience in order to generate a more powerful effect (as for Hartling). Instead, my primary interest was to take that challenge as a basis for fostering group reflection on our interactions during the sessions. I did so by recounting my previous varied experiences with the extent of audience challenge (see section 2), as well as the ways in which audience members frequently justified their behaviour as adhering to social norms - even if though those norms where ambiguous and alternatively conceived.

Clip 7: Bullshit Entertainment magic, according to the ways in which I perform it, is an activity of deception. That is to say, it involves forms of action and inaction intended to mislead audiences. With my honing of simulation and dissimulation techniques over time, it is perhaps not surprising that I came to doubt the veracity of what audiences reported to me and how they responded to my performances. With my growing familiarity with the writings of professional magicians, I have come to understand that I am hardly alone in harbouring such doubts. Outside of entertainment magic too, many lines of sociological and psychological research suggest that the capacity to tell lies and maintain polite fictions is fundamental to social and cognitive development (e.g., Newton et al. 2000; Scott 2015). Indeed, anything approaching complete honesty and forthrightness with one another can be highly threatening for social relations.

How then to make truth and falsity into topics of conversation as part of a magic performance? Although there are a variety of conceptual hooks for doing so (e.g., the act of impostering - see Rappert 2021b), in this clip I did so through the notion of 'bullshit'. Bullshit here refers to a specific epistemic orientation in which attention to the truth and falsity of claims is disregarded (Frankfurt 2005). Stated differently, in bullshitting, the 'facts of the matter' are not treated as relevant considerations. In this clip with the UG group, an Out of this World ${ }^{16}$ trick with an accompanying extrasensory perception patter is used to prompt a discussion about when the truth matters in magic and in everyday life.

\footnotetext{
${ }^{16}$ As with Triumph, many versions of Out of this World exist today. The basic effect though is that audience members select from a pile of face down cards to make sub-piles. The cards are then turned over to reveal they have been sorted into piles, typically a pile of red face cards (the diamonds and hearts suits) and a pile of black face cards (the clubs and spades suits).
} 
Clip 8: Reciprocity The final clip features Tamariz' 'Wisdom'. As part of this trick, each participant in the U3A group undertook a set of manipulations of their own card deck. The conclusion of the effect resulted in two selected cards inexplicably moving from the middle to the top of everyone's deck. This shared undertaking of a trick is used to signal a more general condition; namely, the manner in which entertainment magic is a joint activity wherein audiences and magicians are intertwined in relations of mutual dependency. In this clip as elsewhere in The Magic of Social Life, my interest was in questioning binary oppositions between the magician and their audience and the commonplace tendency to regard (well executed) performances as onedirectional feats of control by the performer. ${ }^{17}$

With these clips and the accompanying text that elaborates these themes discussed, I am currently undertaking initial efforts to use The Magic of Social Life website as part of two main education activities: 1) Student Outreach and Widening Participation in Higher Education sessions with those in school considering social science degrees and 2) Undergraduate tuition - the clips are featuring as supplemental resources in the teaching of an undergraduate module taught be the author on deception.

\section{DISCUSSION}

As an art form that generates affect through displays of the improbable or impossible, entertainment magic is open to serving a wide variety of purposes (e.g., Jones 2012). Landman (2018) signalled one set of possibilities through the notion of 'academic magic'. Central to this sub-genre is the use of magic to communicate fundamental ideas and questions about the human condition. In his case, for instance, magic effects served as a way of illustrating concepts in moral and political philosophy regarding topics such as the good life and social justice. In order to realise this purpose, Landman (2018) set out how his performances seek to disrupt and subvert audiences' assumptions about reality. Working within mentalist traditions, he spoke to an intended overall effect in these terms:

[t]he audience thus sees a show that makes a main claim about a significant idea or concept, which is then explored through increasingly impossible and implausible demonstrations and which then concludes with a final revelation that shows I have known all along what people would do, say, and choose (Landman 2018: 9).

\footnotetext{
${ }_{17}$ The reduction of performances to performers is arguably a commonplace tendency well beyond conjuring, see Whalley and Miller (2017).
} 
Through confounding expectations in this manner, it is possible to create an opportunity for learning.

Sharing in the overall aim of academic magic to speak to the human condition, in this article I have outlined another way to promote learning. In my case, the substantive topic has been the production of everyday social interaction. As elaborated, my overall strategy for performances has been to make our often unexamined social practices and conventions into explicit topics for joint discussion. Rather than disrupting or subverting audiences' assumptions serving as the primary goal, I have sought to foster awareness of what might otherwise be taken-for-granted. Rather than harnessing mental powers with an ambiguously positioned truth status, I have relied on conventionally staged performances with playing cards in order to attend to the contrivances of social life.

As a way of pulling out some of the features noted previously, this article has outlined possibilities for one type of academic magic that has four inter-related features:

- Reflexive: Modern conjuring is a self-referential activity to the extent that performers draw attention to the presence of hidden methods. More than this kind of reflexivity, the sessions discussed asked audience to consciously step back from and monitor their behaviour and beliefs, particularly in relation to the very activity we were undertaking together;

- Emergent: This refers to the manner in which individuals' ongoing reflections during a performance feedback into our unfolding interactions thereby influencing subsequent interactions and the retrospective sense of what took place previously;

- Experimental: As in relation to the overall path of development that informed the topics of The Magic of Social Life, the approach set out has been one of deliberately testing out initial assumptions, provisional conclusions and emerging uncertainties through an iterative process of making them into topics for explicit joint consideration;

- Dialogical: That consideration has been accomplished, in part, through group discussions. Such deliberations have served as a basis for inquiry into how magic is accomplished in practice and also served as part of the ruse works for pulling off effects.

\section{CONCLUSION}

This article has sought to advance the understanding of magic as a form of social interaction. Toward this aim, I have offered a set of possibilities for how attention to the interactional basis for performances, as part of performances, 
can provide opportunities for novel engagements between magicians and audiences. In particular, with the pivot to online communication platforms in response to COVID-19, this article has identified how the bases for technologically-mediated human interactions can serve as topics for joint consideration. In providing these arguments, I have suggested additional rationales for the sub-genre of academic magic and thereby set out additional (educational) purposes for modern conjuring. Overall, I have sought to offer possibilities for how magic can function as a method for understanding ourselves and others. 


\section{REFERENCES}

Atkinson, P. (2013) ‘Blowing Hot’. Qualitative Inquiry 19(5): 397-404.

Armstrong, J. (2019) Insider. 16 December

https://www.vanishingincmagic.com/insider-magic-podcast/

Bell, K. (2012) The Magical Imagination. Cambridge: CUP.

Brown, D. (2003) Absolute Magic. 2nd edition. London: H\&R Magic Books.

Cashman, R., T. Mould, and Shukla, P. (2011) 'Introduction: The Individual and Tradition'. In: R. Cashman, T. Mould and P. Shukla eds. The Individual and Tradition: Folklorist Perspectives. Bloomingtom, IN: Indiana University Press: pp 1-26.

Corrieri, A. (2018) 'What Is This...': Introducing Magic and Theatre'. Platform, 12(2): 12-17.

Dewey, J. (1929) The Quest for Certainty. London: George Allen \& Unwin.

During, S. (2002) Modern Enchantments. London: Harvard University Press.

Frankfurt, H. (2005) On Bullshit. Princeton, NJ: Princeton University Press.

Goffman, E. (1956) The Presentation of Self in Everyday Life. New York, NY:

Doubleday.

Houstoun, W. \& Thompson, S. (2020) 'Are You a Prioritisationalist?'. Video Chat Magic, 7 June

https://videochatmagic.substack.com/p/are-you-a-prioritisationalist

Jones, G. (2011) Trade of the Tricks. London: University of California Press.

Jones, G. (2012) 'Magic with a Message'. Cultural Anthropology, 27(2): pp.193214. doi: https://doi.org/10.1111/j.1548-1360.2012.01140.x

Kuhn, G. (2019) Experiencing the Impossible. Cambridge, MA: MIT Press.

Lamont, P. (2013) Extraordinary Beliefs. Cambridge: CUP. 
Landman, T. (2018) 'Academic Magic: Performance and the Communication of Fundamental Ideas'. Journal of Performance Magic, 5(1).

doi: https://doi.org/10.5920/jpm.2018.02

Livingston, E. (2008) Ethnographies of Reason. London: Routledge.

Hartling, P. [2003] (2013) 'Inducing Challenges'. In: J. Jay ed. Magic in Mind: Essential Essays for Magicians. Sacramento: Vanishing Inc.: pp. 105-112.

Mancha, H. (2016) ‘Daisy Ending'. My Silly Tricks.

Mangan, M. (2007) Performing Dark Arts: A Cultural History of Conjuring. Bristol: Intellect.

McCabe, P. (2020) 'Scripting Magic 2.1 - Part 1'. Video Chat Magic 12 August https:/videochatmagic.substack.com/p/scripting-magic-21

Nardi, P.M. (1988) ‘The Social World of Magicians.' Sex Roles 19(11/12): 759770.

Neale, R. E. (2008) 'Illusions about Illusions'. In: F. Coppa, L. Hass, and J. Peck eds. Performing Magic on the Western Stage: From the Eighteenth Century to the Present. Houndmills: Palgrave.

Newton, P., Reddy, V. \& Bull, R. (2000) 'Children's Everyday Deception and Performance on False-belief Tasks'. The British Journal of Developmental Psychology, 2: pp.297-317. doi: https://doi.org/10.1348/026151000165706

O’Connor, E. (2005) ‘Embodied Knowledge’ Ethnography 6: 183-204.

Olewitz, C. (2020) 'Francis Menotti's Weird Words'. Genii, November: p.39.

Ortiz, D. (1994) Strong Magic. Washington, DC: Kaufman and Company.

Rolfe, C. (2014) 'A Conceptual Outline of Contemporary Magic Practice'. Environment and Planning A, 46: pp.1601-19. doi:

https://doi.org/10.1068/a45501

Pye, D. (2010) 'The Nature and Art of Workmanship'. In G. Adamson ed. The Craft Reader. London: Bloomsbury: pp.341-53. 
Rappert B. (2020) 'Now You See it, Now You Don't: Methods for Perceiving Intersubjectivity.' Qualitative Research, doi:10.1177/1468794120965367

Rappert B. (2021a) "“Pick a Card, Any Card”: Learning to Deceive and Conceal - with Care'. Secrecy and Society, 2(2) doi:10.1177/1468794120965367

Rappert B. (2021b) ‘Conjuring Imposters' In S. Woolgar, E. Vogel, D. Moats and C.F. Helgesson eds. Thinking with Imposters. Bristol: Bristol University Press.

Scott, S. (2015) 'Intimate Deception in Everyday Life'. Studies in Symbolic Interaction, 39: pp.251-279 doi: https://doi.org/10.1108/S01632396(2012)0000039011.

Shezam (2019) ‘Erik Tait on Publishing Magic'. Shezam, Podcast 4014 October. Available at: https://shezampod.com/podcast/40-erik-tait-onpublishing-magic/

Smith, W. (2015) 'Technologies of Stage Magic: Simulation and Dissimulation'. Social Studies of Science, 45(3): pp.319-343.

https://doi.org/10.1177/0306312715577461

Sparkes, A. (2000) 'Autoethnography and Narratives of Self'. Sociology of Sport Journal, 17: pp.21-43. doi: https://doi.org/10.1123/ssj.17.1.21

Steinmeyer, J. (2003) Hiding the Elephant: How Magicians Invented the Impossible and Learned How to Disappear. New York, NY: Carroll and Graf.

Tamariz, J. \& G. Navarro (2008) Verbal Magic. Seattle, WA: Hermetic Press.

Tieber, S. (2020) 'Dealing with Applause, or the Lack Thereof'. Video Chat Magic, 3 September https://videochatmagic.substack.com/p/dealing-withapplause-or-the-lack

Thompson, S. (2020) 'The Folly of the Crowd'. Video Chat Magic, 2 May https://videochatmagic.substack.com/p/the-folly-of-the-crowd

Vernon, D. (1940) Dai Vernon's Select Secrets. New York, NY: Max Holden and Frisch. 
Whalley, J. \& Miller, L. (2017) Between Us: Audiences, Affect and the In-between. London: Palgrave.

Zimmerman, D.H. and Pollner, M. (1971) ‘The Everyday World as a Phenomenon'. In: J.D. Douglas ed., Understanding Everyday

Life. London: Routledge \& Kegan Paul: pp.80-103. 